\title{
COVID-19 in New York City as an Extreme Event: The Disruption and Resumption of the Global City
}

\author{
Steven Cohen \\ School of International and Public Affairs \\ Columbia University \\ 420 West 118th Street, New York \\ NY 10027, USA \\ School of Professional Studies \\ Columbia University \\ 2970 Broadway, MC 4119 \\ New York, NY 10027, USA \\ The Earth Institute, Columbia University \\ 2910 Broadway, Level A, Mail Code 3277 \\ New York, NY 10025, USA \\ sc32@columbia.edu
}

Published

\begin{abstract}
This paper discusses the need for public health infrastructure to address COVID-19 and future pandemics. It then links this need to the centrality of the global economy, and finally to the maintenance of density required for environmentally sustainable cities.

Keywords: Coronavirus; COVID-19; public health; infrastructure; economic development; New York City; environmental sustainability.
\end{abstract}

\section{The Need for Public Health Infrastructure}

While the term extreme event is often used to discuss extreme weather events exacerbated by climate change, the unpredictability of an extreme event and the unpredictability of its impact can also be used to discuss the impact of COVID-19 on New York City. Additionally, the need to mitigate and adapt to these impacts requires the development and operation and management of public health infrastructure, which must be conceptualized, built and operated. In some respects, this is analogous to the security capacity built after 9-11 in New York City. After the 
destruction of the World Trade Center, the security at large buildings and airports tightened and, in New York, an anti-terror unit in the NYPD grew to about 1,000 staff. An anti-terror infrastructure was created to combat terrorism. Today, public health infrastructure must be built to mitigate and adapt to future pandemics.

What would this infrastructure consist of? The first element must be constant screening of the population for contagious conditions. Screening should be a routine requirement for entering transportation hubs, buildings and other institutional settings. Vaccine requirements must be added to travel authorizations such as passports and visas. Once contagious diseases are identified, people with those conditions must be isolated while contagious. Prevention and treatment remedies need to be identified or developed.

It is critical that both low-risk and high-risk individuals be rapidly and routinely identified. People who have been vaccinated against COVID-19 must carry a card that indicates this status and the card must be capable of being read electronically without being shown. People who have been isolated due to the probability that they carry a virus must demonstrate they are no longer contagious and then vaccinated. The electronic card could also report an individual's health status.

The public health infrastructure will require the expansion and maintenance of vastly expanded local, national and global public health capacities. As expensive as this will be, it is less expensive than the trillions of dollars in economic damage brought on by COVID-19. Many of the key elements of what is required have been outlined in President Joseph Biden's COVID-19 plan. It called for the expansion of testing and tracing and rebuilding national and global public health capacities. He also planned to (see, for more details, https://buildbackbetter.com/ priorities/covid-19/):

"Establish a U.S. Public Health Jobs Corps to mobilize at least 100,000 Americans across the country with support from trusted local organizations in communities most at risk to perform culturally competent approaches to contact tracing and protecting at-risk populations.”

\section{Public Health and the Maintenance of the Global Economy}

The investment in public health is needed for the global economy to be revived. Diseases like COVID-19 threaten two key underpinnings of modern economic life: cities and globalization. Authoritarian and nationalistic forces may be seizing on COVID-19 as an opportunity to restrict people and businesses to stay within their borders, but in the long run, the forces of technology, economic development and 
human curiosity will not be contained. Globalization has its downside, making governance in the public interest more difficult and complex, but instead of trying to shut it down, we need to figure out how to make it work. We are a planet that will remain governed by sovereign nations, but we need to get better at regulating global commerce. This is of particular importance to a global city like New York.

Individuals, families, communities and nations pursue self-interest. That is a given. We seek advantage and try to get ahead. But competition does not make cooperation impossible, and global rules of the game can facilitate rather than impede competition. Xenophobia and racism are obstacles to achieving sustainable economic development. Understanding the history and motivation of people from other places can help us learn more about each other, and make cooperation easier and more effective. And the Internet can be a tool for sharing images and information globally. We know it is capable of magnifying disinformation and misunderstanding, but its capacity for truth-telling cannot be understated. In August, 2020 we saw the horrific images of Beirut's explosion. Earlier that year, we viewed the video of George Floyd's murder beneath the knee of a police officer. Those shared images cannot be refuted, and they are shared globally. The planet we live on has been made smaller and more accessible by the World Wide Web. Economic development, like communication, is also global.

Global supply chains are a fact of economic life. They are built on geographic, historic and cultural distinctions between people and places. Different places and people come to specialize in producing different things. We are able to bring those specialties together in a supply chain. These chains rely on inexpensive communication, information and transportation, and enable higher-quality and lowerpriced goods and services. The economic and technological forces behind these trends are irresistible. Nationalist political leaders will lose the battle to influence global corporations if their political strategy does not include an understanding of the economic benefits of globalization.

Rebuilding American manufacturing is a good idea that will diversify our economy, but let us face it, the factories of the future will be largely automated and run from control rooms rather than factory floors. They will not result in mass employment. We are in a brain-based, service-oriented economy. While millions of people became unemployed in the pandemic lockdown of 2020, millions more "worked from home," continuing to produce value for the economy. Some people may like the idea of working from home, but most in 2020 were desperate for a resumption of normal life. Commuting may be annoying, but we like the world we find at both ends of our commute, and few of us seek to merge those worlds. The nature of work has been transformed by technology, and manufacturing is less important than it once was. The hardware in your iPhone is worth much less than 
the software and applications that run on it. The high value-added part of our economy is in creativity, design, communications, strategy and analysis. Manufacturing is necessary, but it is not as profitable as services, including the design of production processes.

Humans are social creatures, and the technologies of communication, information and transportation send many of us all over the world in search of opportunity, travel and productive advantage. Globalization must be tamed rather than eliminated. The advantages of immigration should be obvious in a brain-based economy. If I run an organization and I can recruit my staff from a planet of 7.8 billion people instead of a nation of 331 million, the odds are I will recruit a more talented staff. That means my organization will be more creative and innovative, and that a globally staffed organization will tend to win in a free, competitive marketplace. The nation, city or organization that is most welcoming to people from all over the world and offers the highest quality of life has an edge in the global competition for talent. Regulating and reducing immigration of talented staff to preserve jobs for the less talented local people is a losing strategy.

One of the reasons New York City and other global cities will come back after the extreme event of the COVID-19 pandemic is their attractiveness to talented people. In New York City, 40\% of the people in residence were born in other nations. I was born here, but all of my grandparents were immigrants. New York City's immigrant population does not count my family, and it does not include foreign students, tourists and people here illegally. Young, ambitious and talented people are attracted to the city's energy, dynamism and excitement. The investment in public health infrastructure is a necessary precondition to a return to that world, and it is an investment that most people will support.

Diversity is not simply valuable for reasons of ethics and ideology; it facilitates the creation of groups better able to deal with complexity. Modern production systems are complicated, and have many fixed and moving parts. Think of all the skills and talent required to create a movie. You need experts in storytelling, lighting, filming, sound recording, sound mixing, editing, set construction, acting, directing, costume design, makeup and scores of other skills. When we work to address a problem in my own field of environmental sustainability, we often need lawyers, policy analysts, engineers, health scientists, ecologists, environmental scientists, management specialists, communication specialists and a wide variety of other experts. The life experiences that help build expertise vary. We need people from many places and with many backgrounds, and they need to be good at working in heterogeneous groups. Experience at working in a team with members coming from many places and with varied histories is a particularly sought after 21st-century professional skill. 
These fundamentals of global production will gradually return in the postCOVID era. The communities that are built for homogeneity will lose to those built for diversity. Communities that welcome people with different backgrounds will be better able to attract the talent needed to compete. With few exceptions, we are a nation of immigrants. Some of us were brought here unwillingly, and others came illegally, but the United States is the planet's most global nation, and New York is America's most global city. That diversity is a great advantage in the competition to attract talent from every corner of the world.

\section{Public Health, Density and the Sustainable City}

Unless we can regain the advantages of density post-COVID-19, the move toward sustainability will be impaired due to the demise of the sustainable city. The spread of the coronavirus and the need for social distancing have been seen by some as a fundamental challenge to globalism, population density and urban life. The virus is both a challenge and a catastrophe, but it does not change the basic appeal and benefit of our way of life. While wealthy people in this era of extreme income inequality sought to find a safe haven from contamination, as the virus spreads into rural America, it becomes clear that you can run from the modern world, but you cannot hide from it. Cities, suburbs or the countryside: Everyone is in the pathway of exposure.

My view of environmental sustainability centers on the goal of developing sustainable cities that provide energy, transport, entertainment, education, social engagement, food, clothing and shelter with the least possible impact on the planet's ecosystems. We concentrate people in beautiful and exciting cities and leave as much of nature alone as we can. This requires population density to support economies of scale coupled with decentralized energy, food, transport, water and waste systems that permit resiliency and safety. In the first edition of my book, The Sustainable City, I discussed the infrastructure needed to support a sustainable city: sustainable energy, water, food, transport, waste management and open space. In the second edition, co-authored with my colleague Dong Guo, we have added another piece of essential infrastructure: a competent and well-resourced system of public health. In order to facilitate the density needed for dynamic cities built with renewable, circular economies, people must feel free from the threat of pandemics.

One of the great benefits of the sustainable lifestyle is its emphasis on social engagement and interaction. Cities enable enjoyment of public spaces, the arts and the diversity of a city's neighborhoods. The goal is to engage in experiences rather than ownership and consumption. This enables economic activity with relatively low levels of environmental impact. People enjoy parks instead of private gardens, 
theaters instead of private screening rooms and mass transit, walking or biking instead of personal transport. They view rather than own art and live in smaller private spaces due to their easy access to diverse public spaces.

During the difficult days of pandemic-induced isolation, some city dwellers wondered if they would have been better off in the suburbs, and some moved to their country homes or parents' homes in the suburbs. If this were a permanent change, many asked about its impact on cities? Similar questions were asked about the global travel industry, about convention and event businesses and even about professional sports. My view of this is that cities, travel and the global economy developed because of the benefits they provide, and this pandemic has not ended those benefits but made us painfully aware of how much we miss them when they are gone.

With trillions of dollars in play, the need for enhanced public health systems is clear. It is true that on a more populated planet in a global economy, COVID-19 will not be the last pandemic we will see. We will be challenged by other diseases. But just as global terrorism led to airport searches, video surveillance and massive institutional capacity to track and prevent terror, this pandemic will lead to increased capacity to track, prevent and treat disease.

This will happen because we do not want to live lifestyles defined by social distancing. We want social engagement and social interaction. We want to hear people laughing and crying at the theater, we want to see children playing in the playground in public parks. Zoom is a great tool, but it is not a replacement for the real world. The COVID-19 crisis has had a massive and negative impact globally and on New York City, but it is easy to envision a solution that can address this extreme event and enable us to resume building a more sustainable New York City. 